\title{
Effects of deprivation schedule on the maintenance of a preoperative salt aversion by adrenalectomized rats*
}

\author{
KENNETH FRUMKIN $\dagger$ \\ McGill University, Montreal, Quebec, Canada
}

\begin{abstract}
Rats that had learned a conditioned taste aversion to $\mathrm{NaCl}$ were subsequently adrenalectomized or sham-operated. In the first experiment, all animals had $1 \mathrm{~h}$ of daily access to a salt solution and water postoperatively. A majority of the adrenalectomized animals maintained their aversions postoperatively and died. In the second study, the effects of the preoperative aversion were all but eliminated in adrenalectomized animals by giving ad lib access to sodium and water postoperatively. It was concluded that "modifiability" of the sodium appetite can be demonstrated only under restricted deprivation conditions.
\end{abstract}

Rats that are poisoned after drinking a distinctively flavored fluid will learn to avoid that flavor in the future. Such conditioned taste aversions can be acquired after only one trial, and are extremely resistant to extinction (Garcia, McGowan, \& Green, 1971). A strong, long-lasting aversion to sodium chloride $(\mathrm{NaCl})$ solutions can be conditioned in the rat by allowing the animal to drink an equimolar solution of poisonous lithium chloride ( $\mathrm{LiCl}$ ) (Fregly, 1958; Smith \& Balagura, 1969). $\mathrm{LiCl}$ is not discriminated from $\mathrm{NaCl}$ in short-term tests by either normal or adrenalectomized rats (Balagura, Brophy, \& Devenport, 1972; Nachman 1963a,b).

A number of Es have used this powerful learning paradigm in attempts to modify the unlearned appetite for sodium exhibited by sodium-deficient rats. 1 The majority have been unsuccessful. For example, Stricker and Wilson (1970) found that rats that had learned to completely avoid an $\mathrm{LiCl}$ solution after a series of exposures would return to drink it when they were depleted of sodium. Balagura and Smith (1970) observed that sodium-deficient rats overcame prior sodium aversions after only a few hours of exposure to salt. Similarly. Frumkin (1971) reported that rats quickly overcame their LiCl-induced salt-avoidance after adrenalectomy.

Results contradictory to these have been published by Cullen (1970). For 8 days he exposed rats to a choice between $\mathrm{LiCl}$ and either water or saline. Half of his $\mathrm{Ss}$ were then adrenalectomized, and all were given a choice between $\mathrm{NaCl}$ and sucrose solutions. Postoperatively, the

\footnotetext{
This paper is based on portions of a doctoral dissertation submitted to McGill University. The research was supported by Grant PA 66 from the National Research Council of Canada to Peter M. Milner. The help of $P$. Milner and $A$. Pert in reviewing this manuscript is gratefully acknowledged. The author would also like to thank David Cohen, Sheila Daykin, Susan Jones, and Elliot Kravitz for their able assistance in various phases of this work.

tNow at Hahnemann Medical College, Box 414, 245 North Fifteenth Street, Philadelphia 19102. Requests for reprints should be sent to Peter M. Milner, Department of Psychology, McGill University, P. O. Box 6070, Montreal 101, Quebeo.
}

adrenalectomized animals in his study drank even less salt than sham-operated rats did.

Balagura et al (1972) recently attempted to resolve the conflict between the results of the Frumkin (1971) and Cullen (1970) experiments. They varied the amount of experience with $\mathrm{LiCl}$ prior to sodium depletion. Like Cullen (1970), they found a modification of the sodium appetite. Rats that had been given a large number of exposures to $\mathrm{LiCl}$ (up to 16) "failed to overcome their learned $\mathrm{NaCl}$ aversion when a severe sodium depletion was induced by Formalin or adrenalectomy [Balagura et al, 1972, p. 212]." Their conclusion was that the "intensity (strength) of the learned $\mathrm{NaCl}$ aversion may be modified by experience, and can account for many of the apparent discrepancies in previously reported experiments [p. 212]."

Besides the strength of the initial aversion, there is one other variable that could account for the differences between at least two of the conflicting experiments-the duration of the daily testing period. In the Balagura et al (1972) study, rats that maintained their sodium aversion in the face of salt depletion had access to $\mathrm{NaCl}$ for only $1 \mathrm{~h} /$ day, followed by $5 \mathrm{~h}$ of water alone. In the Frumkin (1971) study, Ss had a 24-h choice between $\mathrm{NaCl}$ and water, and quickly overcame their preoperative $\mathrm{LiCl}-\mathrm{NaCl}$ aversion.

This paper reports on two experiments in which rats were adrenalectomized after having developed a strong aversion to $\mathrm{NaCl}$. In the first study, Ss with only $1 \mathrm{~h}$ of daily salt exposure maintained their preoperative sodium aversion, behaving like the animals on the Balagura et al (1972) study. In the second experiment, when $\mathrm{NaCl}$ was available $24 \mathrm{~h} /$ day, the aversion was rapidly overcome (resembling the Frumkin, 1971, data).

\section{EXPERIMENT I}

In the first experiment, rats were injected with $\mathrm{LiCl}$ on three occasions after drinking $\mathrm{NaCl}$ for $1 \mathrm{~h}$. The effects of adrenalectomy on the salt aversion produced 


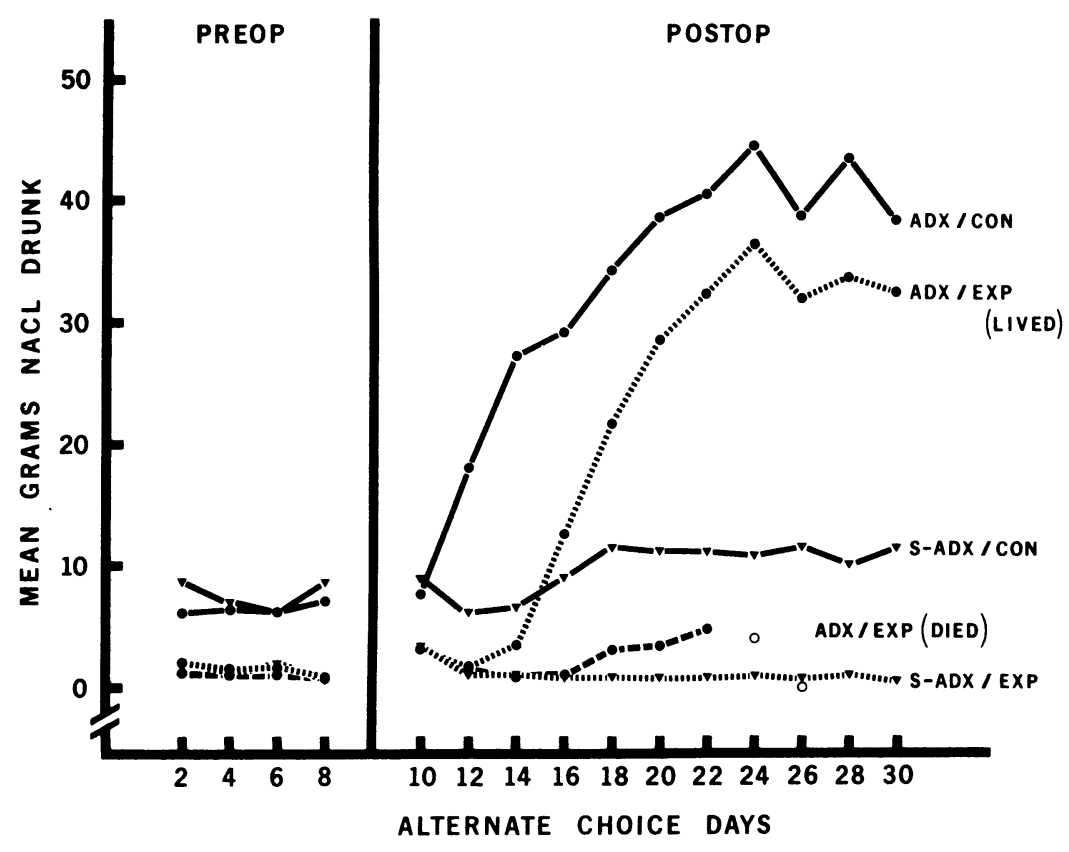

Fig. 1. Mean number of grams of $\mathrm{NaCl}$ drunk on alternate choice days by $S s$ in Experiment I. The data from the ADX/EXP Ss that died are presented separately (dashed lines) from those of the survivors (dotted lines). Open symbols represent data from three or fewer Ss. by this treatment were studied in a series of 1 -h choices between $\mathrm{NaCl}$ and water. Injected $\mathrm{LiCl}$ was used (as opposed to allowing the animals to drink $\mathrm{LiCl}$ ) because Harriman, Nance, and Milner (1968) have reported that adrenalectomized rats can discriminate between equimolar $\mathrm{NaCl}$ and $\mathrm{LiCl}$, even in the first few minutes of repeated tests.

\section{Method}

Subjects and Apparatus. Forty-nine naive male Sprague-Dawley rats, weighing 325-350 g, were purchased from Canadian Breeding Farms, St. Constant, Quebec. They were housed individually in metal-topped plastic cages and were maintained on ad lib Purina Rat Chow for the duration of the experiment (Purina Rat Chow contains approximately $0.42 \%$ sodium, by weight). Fluids were presented in bottles with straight metal drinking tubes projecting into the cage from the top. When two bottles were presented, their tubes were 3-4 in. apart. To control for position preferences, the daily location of each bottle was systematically varied. Fluid consumption was determined by subtracting the weight of the bottle at the end of a drinking period from its weight at the beginning of that period. A maximum of $1.0 \mathrm{~g} /$ day was lost by spillage. Drinking solutions were distilled water and $0.9 \% \mathrm{NaCl}$.

Procedure. Cond itioned aversion training began after 7 days of adaptation to a 23-h water-deprivation schedule. On Day 1, a single bottle of $0.9 \% \mathrm{NaCl}$ was presented for $1 \mathrm{~h}$. Experimental Ss $(N=25)$ were injected (IP) with $2 \%$ of body weight of $0.15 \mathrm{M}$ $\mathrm{LiCl}, 1-10 \mathrm{~min}$ after the end of the drinking period (Nachman, 1970). Control groups were injected with an equal volume of $0.15 \mathrm{M} \mathrm{NaCl}$. On the second day, all animals had a 1-h choice between $\mathrm{NaCl}$ and distilled water. The first day's injection procedure was repeated on Days 3 and 5. A 1-h choice was presented again on Day 4, and daily from Day 6 to the end of the experiment (Day 30).

Operations took place following the drinking period on Day 9. Eight animals from each of the groups were sham-adrenalectomized, forming the S-ADX/EXP and $S-A D X / C O N$ groups. The remaining $S s$ were all adrenalectomized - these made up the ADX/EXP and ADX/CON groups. The bilateral adrenalectomies were performed under ether anesthesia. The procedure for the sham operation was identical to that for complete adrenalectomy, except that the adrenals were not disturbed.

At the end of the experiment, all surviving $S s$ in the adrenalectomized groups were placed on an ad lib sodium-free diet of potatoes boiled in distilled water. Boiled potatoes contain approximately $0.003 \%$ sodium, by weight (Bowes \& Church, 1966). Only those rats that died within 18 days of being placed on this diet were considered to have been completely adrenalectomized, since rats with complete adrenalectomy do not live longer than 18 days without supplementary $\mathrm{NaCl}$ (Gaunt, Tobin, \& Gaunt, 1935). One S was discarded for failing to meet this criterion. Of six randomly selected sham-operated rats placed on the same diet, one died inexplicably and the other five gained an averaged of $23.2 \mathrm{~g}$. Because one ADX/CON S had to be discarded due to experimental error, the final number of animals in each adrenalectomized group was 16 and 15 for the ADX/EXP and ADX/CON groups, respectively. There were eight rats in each of the sham-operated groups.

\section{Results}

Statistical comparisons between groups of Ss were made using the two-tailed Mann-Whitney U test (M-W). Changes within the same group of Ss over time were evaluated with the two-tailed Wilcoxon matched-pairs signed-ranks test (WT) (Siegel, 1956).

This study's most significant finding was the failury of 9 of the $16 \mathrm{Ss}$ in the ADX/EXP group (56.2\%) to increase their salt intake after adrenalectomy. These animals maintained their preoperative aversion to $\mathrm{NaCl}$, and, as a result, died in an average of 13.1 days, postoperatively. The seven surviving animals in this group did overcome their salt aversion and display a sodium hunger.

Figure 1 presents mean $\mathrm{NaCl}$ intake for each group on alternate choice days. The data from ADX/EXP Ss that died are presented separately (dashed lines) from the 
Fig. 2. Mean body weight (in grams) on alternate choice days for groups in Experiment I. The data from the ADX/EXP Ss that died are presented separately (dashed lines) from those of the survivors (dotted lines). Open symbols represent data from three or fewer Ss.

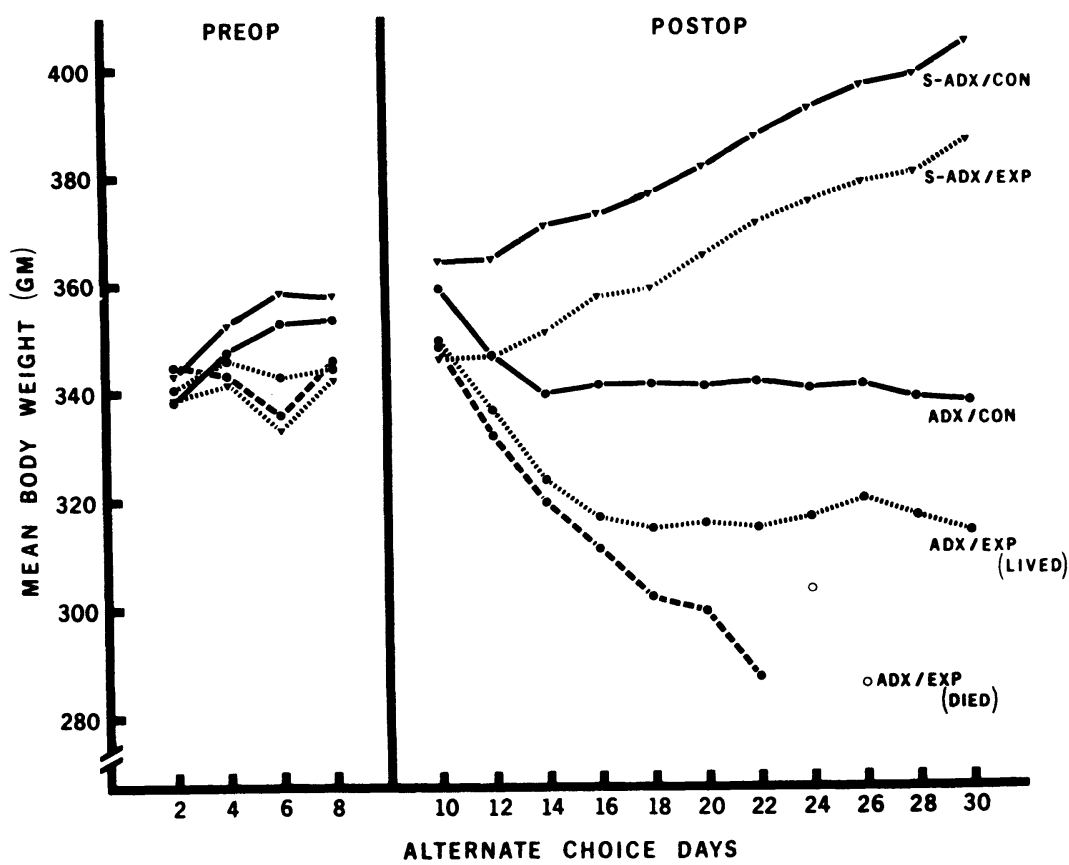

In general, water intake varied reciprocally with $\mathrm{NaCl}$ ingestion, and is not reported. The only exception was in the postoperative water intake of the dying ADX/EXP Ss. Water intake for these animals decreased postoperatively.

Body weight changes seen in Fig. 2 followed expected patterns. Preoperatively, no significant differences in mean body weight were found between any of the groups ( $p s>.10, M-W)$. Postoperatively, both sham-adrenalectomized groups gained weight (a mean of $40.0 \mathrm{~g}$ ) from the first postoperative day to the end of the experiment ( $\mathrm{ps}=.01$, WT). No differences in body weight were found between the two sham-operated groups on any postoperative day ( $p s>.05, \mathrm{M}-\mathrm{W})$. All ADX/EXP Ss lost weight (a mean of $52.1 \mathrm{~g}$ ) from Day 10 to the end of testing (ps $<.02$, WT). No weight differences were found between the surviving and the nonsurviving members of this group ( $p s>.05 . \mathrm{M}-\mathrm{W}$ ). The ADX/CON Ss also lost weight from Day 10 to Day $30 \quad(\mathrm{p}<.01$, WT). However, their weight loss (mean $=22.6 \mathrm{~g}$ ) was not as severe as that suffered by the ADX/EXP group. The body weight differences between the ADX/CON and the two ADX/EXP groups were significant on all days after Day 13 (ps $<.02$ ).

The dramatic postoperative differences between the two subgroups in the ADX/EXP condition probably reflect individual variation in the degree of the conditioned taste aversion established preoperatively (Balagura et al, 1972). Evidence for this comes from a comparison of the preoperative drinking of the two subgroups. When the mean $\mathrm{NaCl}$ consumption over all preoperative choice days was compared, the survivors were found to have drunk slightly, but significantly, more $\mathrm{NaCl}$ than the Ss that died postoperatively (1.4 vs $1.0 \mathrm{~g} ; \mathrm{p}<.02, \mathrm{M}-\mathrm{W})$. This difference in preoperative intake was also found on days when only single bottles 


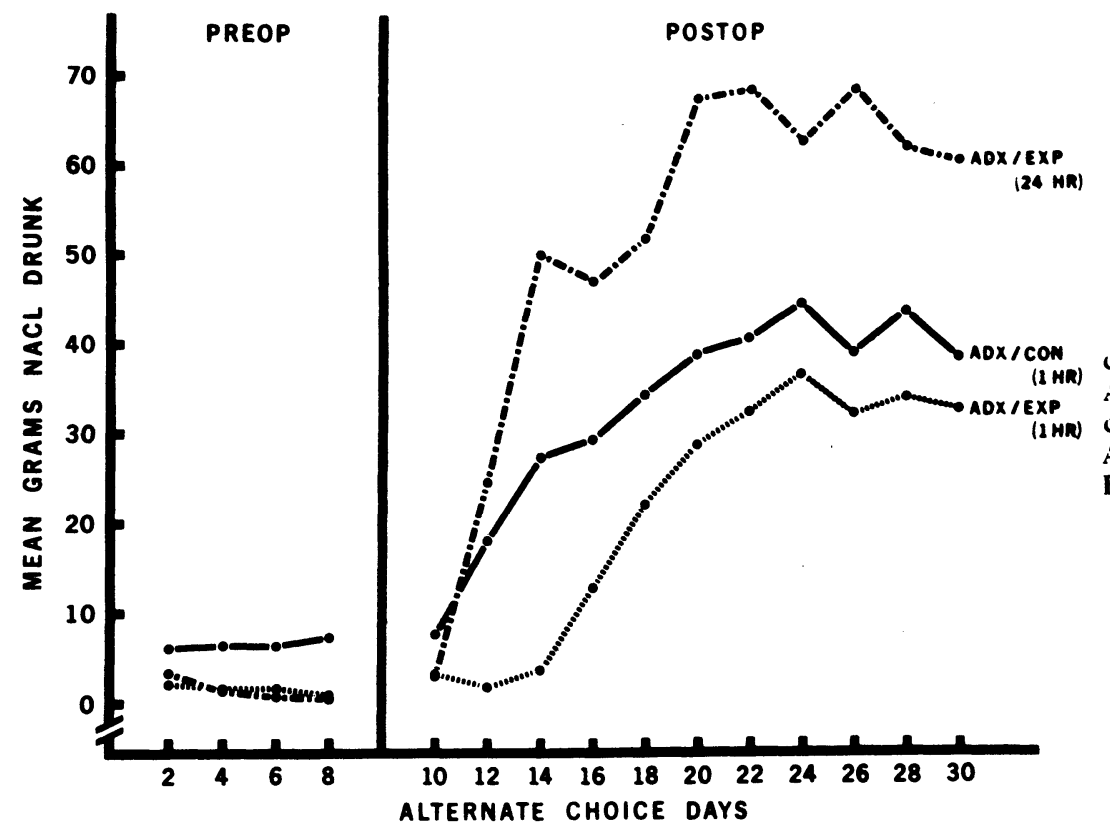

Fig. 3. Mean number of grams of $\mathrm{NaCl}$ drunk on alternate choice days by ADX/EXP Ss in Experiment II $(24 \mathrm{~h})$, compared with the $\mathrm{NaCl}$ intake of the ADX/CON and ADX/EXP groups from Experiment I (1 h).

of $\mathrm{NaCl}$ were presented. The amount of salt drunk on Days 3 and 5 by the survivors (28.1 and $14.9 \mathrm{~g}$, respectively) was significantly greater than the amounts consumed by the animals that died (18.6 and $3.6 \mathrm{~g}$; ps $<.02, \mathrm{M}-\mathrm{W})$. There was no difference in $\mathrm{NaCl}$ consumption of the first test day, prior to the initial $\mathrm{LiCl}$ injection $(\mathrm{p}>.10, \mathrm{M}-\mathrm{W})$.

\section{Discussion}

The data of Experiment I seem to give strong support to the Balagura et al (1972) hypothesis that a strong preoperative salt aversion will inhibit the development of the sodium appetite in salt-deficient rats. The stronger the preoperative aversion, the more likely it is to persist after adrenalectomy. This effect is so overpowering that a large percentage of these animals died rather than drink the available salt solution. The findings are analogous to Richter's (1953) report that rats would starve to death rather than accept previously poisoned foods.

The data from those ADX/EXP Ss that overcame their aversion do not seem to indicate any lasting alterations of sodium preference. The survivors eventually reached the same level of $\mathrm{NaCl}$ consumption as the adrenalectomized control Ss. The initial aversion did have some effects on the surviving animals-they weighed less throughout the postoperative period, and they died in a shorter time than controls did when placed on the deficient diet (3.7 vs 6.1 days; $p<.02$, $\mathrm{M}-\mathrm{W})$.

The results also appear to support Cullen (1970). However, his findings differ from those of the present study in a number of respects. In spite of the aversiveness of his preoperative $\mathrm{LiCl}$ exposures (which led to the death of $16 \%$ of his Ss), sham-operated rats did not subsequently avoid $\mathrm{NaCl}$. In fact, they drank
$14.6 \mathrm{ml} / 100 \mathrm{~g}$ body weight [around $33 \mathrm{ml} /$ day by conservative calculation from Cullen, 1970, (Figs. 1 and 2)]. Sham-adrenalectomized experimental $\mathrm{Ss}$ in the present study drank around $1 \mathrm{~g} \mathrm{NaCl} /$ day. It is also important to note that while Cullen's adrenalectomized Ss did drink less than sham-operates, they were drinking around $20 \mathrm{ml}$ of $\mathrm{NaCl}$ daily (by calculation from his figures), which was enough to keep all but four Ss (89\%) alive. That drinking pattern is quite different from this study, in which the ADX/EXP Ss either drank no salt at all and died or drank as much as controls and survived.

\section{EXPERIMENT II}

In this study, Ss received the same preoperative aversion training as the animals in the ADX/EXP and S-ADX/EXP groups of Experiment I. However, after adrenalectomy, they were given ad lib access to $\mathrm{NaCl}$ and distilled water, rather than the daily $1-\mathrm{h}$ exposures used in the preceding study.

\section{Method}

The 15 Ss were from the same source and were the same weight as those in Experiment I. Treatment prior to adrenalectomy was identical to that given the experimental groups in that study. Beginning on the first day after the operation (Day 10), bottles were left on the cages $24 \mathrm{~h} /$ day. Ad lib access to $\mathrm{NaCl}$ and water was continued until the end of the experiment (Day 30). One rat did not meet the criterion for complete adrenalectomy and was discarded from the study.

\section{Results and Discussion}

Contrary to the previous findings, 13 of the 14 rats in this group recovered from their preoperative aversions and developed strong sodium appetites after adrenalectomy. One animal maintained an aversion and died. The most salt consumed by that $S$ on any 
Fig. 4. Mean body weight (in grams) on alternate choice days for the ADX/EXP Ss in Experiment II (24 h), compared with the mean body weights of the ADX/CON and ADX/EXP groups from Experiment I (1 h).

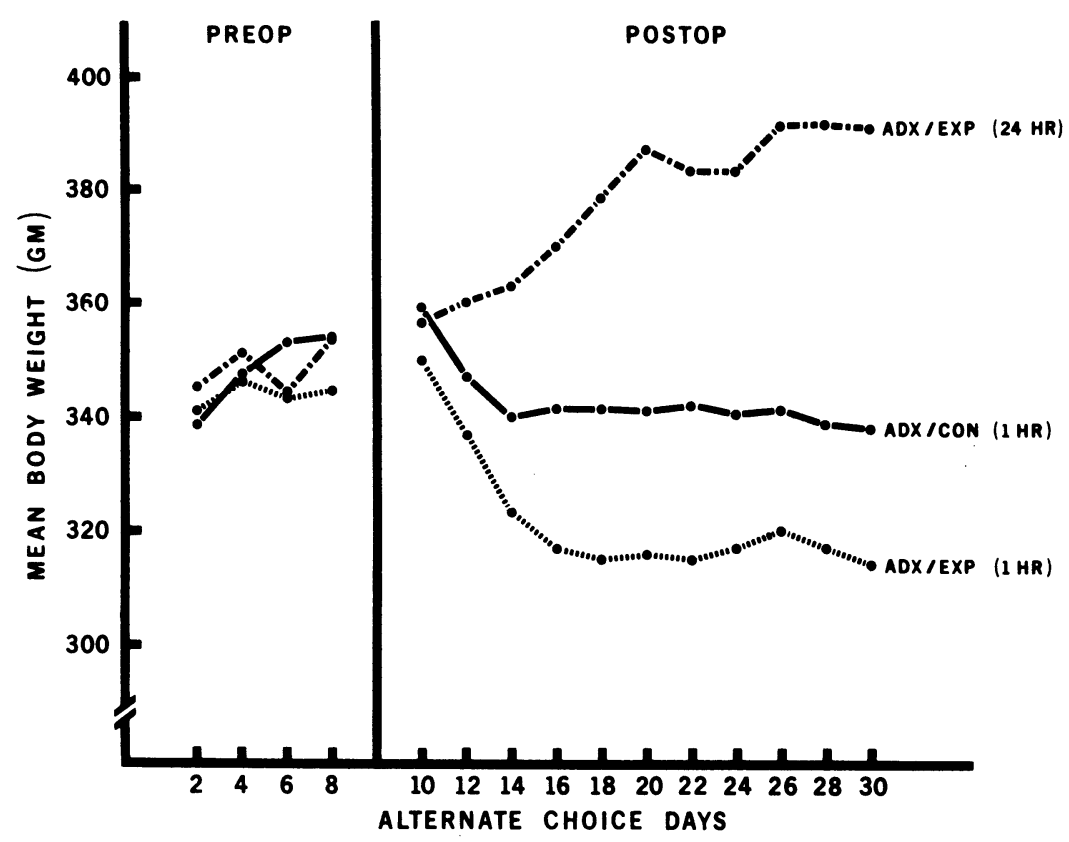

postoperative day was $5 \mathrm{~g}$. The data from that animal were not included in the figures and analyses. ${ }^{2}$

For purposes of comparison, Figs. 3 and 4 present the data from this study (the 24-h ADX/EXP group) along with those from the $\mathrm{ADX} / \mathrm{CON}$ and the surviving ADX/EXP (1-h) groups from Experiment I. Figure 3 shows. salt intake on alternate choice days, both pre- and postoperatively. Before the operation, when all three groups had only $1 \mathrm{~h}$ to drink, the mean daily intake of the two experimental groups was identical $(p>.10$, $\mathrm{M}-\mathrm{W})$, and both groups drank less salt than control Ss (ps<.002, M-W). On the first postoperative day (10) there was still no difference in intake between the ADX/EXP Ss with 1-h and those with 24-h exposure to salt $(p>.10, M-W)$. However, the Ss in this study rapidly overcame their aversion and surpassed the intake of the 1-h group by the end of Day $11(\mathrm{p}<.002, \mathrm{M}-\mathrm{W})$. It is also evident that 24-h access produced more salt drinking in experimental animals than that exhibited by control Ss having only a 1 -h daily exposure. The difference between the ADX/EXP (24-h) group and the $\mathrm{ADX} / \mathrm{CON}$ Ss was significant on and after Day 14 (ps $<.05$ for Days 14-30, M-W). The final level of sodium intake attained by the Ss in this study (around $60-65 \mathrm{~g} /$ day) is virtually identical with that observed previously in adrenalectomized rats with 24-h salt access (Frumkin, 1971, Fig. 2).

Figure 4 presents the mean body weights for the same three groups. It can be seen that body weight is very highly correlated with salt drinking. The group having ad lib access gained an average of $36 \mathrm{~g}$ from Day 10 to Day 30 ( $p<.01$, WT), while both groups with 1 h of salt lost weight during the same period.

The results of Experiment II clearly support the previous findings (Frumkin, 1971). In addition, they resemble an earlier study by Cullen (1969) in which rats, prior to adrenalectomy, received three exposures to radiation sickness while drinking $\mathrm{NaCl}$. Postoperatively, Cullen's (1969) Ss, with an ad lib choice between saccharin and $\mathrm{NaCl}$, demonstrated only a "short-lived" salt aversion. Within 7 days after adrenalectomy, his animals were gaining weight and drinking the same amount of salt as adrenalectomized controls. Sham-operated rats continued to avoid sodium.

The present findings are, however, quite dissimilar from those of Experiment I and the Balagura et al (1972) study, in which preoperative aversions were maintained if salt-deficient rats had sodium for only $1 \mathrm{~h} /$ day. Twenty-four-hour access alone, without the added stimulus of salt hunger is not sufficient to produce the extinction, since sham-adrenalectomized rats with ad lib salt will maintain a preoperatively conditioned sodium aversion for as long as 20 days (Cullen, 1969; Frumkin, 1971). These findings make the Cullen (1970) report, discussed in Experiment I, seem even more surprising, since his animals also had ad lib $\mathrm{NaCl}$ (vs a glucose solution) postoperatively.

It is unlikely that the strength of the aversion (Balagura et al, 1972) had much effect in this study, since the preoperative aversions in Experiment II were among the strongest measured (less than $1 \mathrm{~g} / \mathrm{day}$, including spillage). However, the failure of 1 of the $14 \mathrm{Ss}$ to overcome the aversion may have been due to such a factor.

\section{GENERAL DISCUSSION}

The present results help to clarify the role of prior salt aversions in the "modifiability" of the sodium-specific hunger. Adrenalectomized rats will maintain a preoperatively conditioned salt aversion if given access to sodium for only $1 \mathrm{~h} /$ day (Experiment I; Balagura 
et al, 1972). However, they will quickly overcome their aversion if the drinking period is cxtended to $3 \mathrm{~h}$ (Balagura \& Smith, 1970), or if ad lib access is given (Experiment II; Cullen, 1969; Frumkin. 1971).

It is unlikely that both of these mutually exclusive phenomena are relevant to predicting behavior in the animals' natural environment. However. given the low probability of a wild rat's finding itself on a 23-h deprivation schedule, it is most likely that the results of Experiment II are representative. It seems safe to conclude, then, that convincing evidence for "modification" of the sodium appetite by aversion conditioning exists only when rats are kept on a very restricted fluid-deprivation schedule. ${ }^{3}$ As was concluded in the earlier report (Frumkin. 1971). the level of sodium need, rather than past experience. seems to have the greatest influence on salt regulation in the adrenalectomized rat.

\section{REFERENCES}

Balagura, S Brophy, J \& Devenport, L. D. Modification of learned aversion to $\mathrm{LiCl}$ and $\mathrm{NaCl}$ by multiple experiences with Licl. Journal of Comparative \& Physiological Psychology, 1972, 81, 212-219.

Balagura, S., \& Smith, D. F. Role of $\mathrm{LiCl}$ and environmental stimuli on generalized learned aversion to $\mathrm{NaCl}$ in the rat. American Journal of Physiology, 1970, 219, 1231-1234.

Bowes, A., \& Church, C. F. Food values of portions commonly used. (10th ed.) Philadelphia: Lip pincott, 1966.

Cullen, J. W. Modification of salt-seeking behavior in the adrenalectomized rat via gamma-ray irradiation. Journal of Comparative \& Physiological Psychology, 1969, 68, 524-529.

Cullen, J. W. Modification of $\mathrm{NaCl}$ appetite in the adrenalectomized rat consequent to extensive $\mathrm{LiCl}$ poisoning. Journal of Comparative \& Physiological Psychology, 1970, 72 , 79-84.

Fregley, M. J. Specificity of the sodium chloride appetite of adrenalectomized rats: Substitution of lithium chloride for sodium chloride. American Journal of Physiology, 1958, 195, 645-653.

Frumkin, $\mathrm{K}$. Interaction of $\mathrm{LiCl}$ aversion and sodium-specific hunger in the adrenalectomized rat. Journal of Comparative \& Physiological Psychology, 1971, 75, 32-40.

Garcia, J., McGowan, B. K., \& Green, K. F. Biological constraints on conditioning. In $A$. Black and W. F. Prokasy (Eds.), Classical conditioning. New York: A ppleton-Century-Crofts, 1971

Gaunt, R., Tobin, E. E., \& Gaunt, J. H. The survival of salt-treated adrenalectomized rats. American Journal of Physiology, 1935, 111, 321-329.

Handal, P. J. Immediate acceptance of sodium salts by sodium deficient rats. Psychonomic Science, 1965, 3, 315-316.
Harriman. A. F., Nance. I). M., \& Milner. (). S. Discrimination between equimolar $\mathrm{NaCl}$ and $\mathrm{LiCl}$ solutions by anosmic. adrenalectomized rats. Physiology \& Behavior, 1968, 3 . 887-889.

Nachman. M. Taste preferences for sodium salts by adrenalectomized rats. Tournal of comparative \& Phrsiological Psychology, 1962, 55, $1124-1129$

Nachman. M. Learned aversion to the taste of lithium chloride and generalization to other salts. Journal of (omparative \& Physiological Psychology, 1963a, 56, 3+3-349

Nachman, M. Taste preferences for lithium chloride by adrenalectomized rats. American Iournal of Phvsiologs, $1963 \mathrm{~b}, 205,219-221$.

Nachman. M. Learned taste and temperature aversions due to lithium chioride sickness after temporal delays. Journal of Comparative \& Physiological Psychology, 1970, 73, 22-30.

Richter. C. P. Experimentally produced behavior reactions to food poisoning in $w$ ild and domesticated rats. Annals of the New York Academy of Sciences, 1953, 56, 225-239.

Rodgers. W. L. Specificity of specific hungers. Journal of Comparative \& Physiological Psychology, $1967,64,49-58$.

Rozin, P. \& Kalat, J. W. Specific hungers and poison avoidance as adaptive specializations of learning. Psychological Review, $1971,78,459-486$.

Siegel. S. Nonparametric statistics for the behatioral sciences. New York: McGraw-Hill, 1956.

Smith, D. F., \& Balagura, S. Role of oropharyngeal factors in LiCl aversion. Journal of Comparative \& Physiological Psychology, 1969,69, 308-310.

Stricker, E. M.. \& Wilson, N. E. Salt-seeking beharior in rats following acute sodium deficiency. Journal of Comparative \& Physiological Psychology, 1970, 72, 416-420.

Wolf, G. Innate mechanisms for regulation of sodium intake. In C. Pfaffman (Ed.), Olfaction and taste. Vol. 3. New York: Rockefeller University Press, 1969.

\section{NOTES}

1. Although learning plays the primary role in the development of most specific hungers (Rodgers, 1967), there is considerable evidence that the sodium appetite represents an innate regulatory mechanism (see Rozin \& Kalat, 1971; Wolf, 1969). For example, salt-deficient rats will demonstrate an increased preference for $\mathrm{NaCl}$ solutions $w$ ithin the first $15 \mathrm{sec}$ of exposure, too soon for any reinforcement to have occurred (Handal, 1965; Nachman, 1962).

2. Decisions to include (Experiment I) or eliminate (Experiment II) from the data the Ss that died were reached arbitrarily in order to make the figures most representative of the overall findings. In neither case did the change alter the statistical significance of any of the results.

3. There is still no explanation for the Cullen (1970) results that is consistent $w i t h$ the rest of the literature. His findings are unusual in a number of respects (see Frumkin, 1971, and the discussion of Experiment I), and may possibly be explained by differences in Ss and procedure between his experiment and others.

(Received for publication January 21, 1974; accepted July 11, 1974.) 